\title{
A função do defensor dos interesses do Estado no processo administrativo-tributário
}

\section{Gentil André Olsson}

Defensor da Fazenda Estadual junto ao

Tribunal Administrativo de Recursos Fiscais-RS.

Junto aos órgãos colegiados estaduais de julgamento do contencioso tributário administrativo, atuam, como defensores dos in teresses do erário público, Procuradores do Estado (CE, SE, PE, MS e DF), Procuradores Fiscais (MG, BA e SC) e "Representantes Fiscais" ou "Defensores da Fazenda" (RJ, GO, PR, SP, RO e RS).

Os primeiros provêm dos quadros da respectiva Procuradoria do Estado, e o segundo grupo é oriundo dos quadros da Procuradoria Fiscal do respectivo Estado. Os demais, são recrutados entre funcionários dos quadros da Secretária da Fazenda ou Finanças (geralmente do quadro de Fiscais ou equivalente ou do Departamento Jurídico da Secretaria da Fazenda) e designados para a função, pelo respectivo Secretário de Estado, por prazo indeterminado, e por ele dispensáveis ad nutum. Em alguns Estados, como o Rio Grande do Sul, a função é privativa de "Fiscal de Tributos Estaduais, bacharel em Ciências Jurídicas e Sociais".

As atribuições do "Defensor dos interesses da Fazenda" junto aos Conselhos (AC, AM, AP, AL, CE, RO, SE, SC, ES, TO, BA GO, RR, MT, PA, MA, MS, MG, PR, PB, RJ e RN), Tribunais (PE, RS, e SP) ou Junta (DF), definidas na legislação das diversas Unidades Federadas, podem ser agrupadas em quatro áreas de atuação:

Nota: tendo em vista que não dispúnhamos da legislação completa de todas as Unidades da Federação, as siglas colocadas entre parênteses têm caráter meramente exemplificativo.

I - Atuação, no interesse da Fazenda, nos recursos interpostos pelo sujeito passivo do crédito tributário; aão (MS), em sua composição plena (Conselho Pleno - RJ, GO e PR ou Tribunal Pleno - RS e PE).

Este recurso recebe diversos nomes, tais como: Embargos (GO), Recursos Extraordinários (RS), Recurso de Reconsideração (PR), Recurso Voluntário (PE), Recurso ao Conselho Pleno (RJ) e Pedido de Reconsideração (MS).

Existem Estados cuja legislação admite Pedido de Reconsideração (RS e PE) ou Recurso Extraordinário (CE) das decisões de Câmaras que tenham dado provimento a recurso de ofício (CE e RS); outros condicionam, ainda, que a decisão reconsiderada não seja unânime e tenha confirmado decisão absolutória de primeira instância (PE).

Quando a Decisão de Câmara, Turma ou Junta divergir de outra de órgão de igual hierarquia ou de órgão em composição plena ou Câmara Superior, cabem Recurso Especial (CE), Recurso de Reconsideração (PR); Recurso de Revista (MG e BA); Recursos de Revisão (RO); Recurso Voluntário (PE); "Recurso ao Pleno" (RJ), Recurso Extraordinário (RS) e Pedido de Revisão (SP)

Além de outros procedimentos incidentais de iniciativa do sujeito passivo, algumas Unidades prevêem: "impugnação" ao arquivamento de recursos por intempestivo (RR e PR), "Recurso contra decisão do Presidente" (DF), "Exceção de Suspeição" (DF), Revisão por vício processual que acarrete cerceamento da defesa (DF) e Pedido de Esclarecimento ao respectivo órgão de decisão omissa, obscura ou contraditória (RS e PR).

Cabe ao "defensor" o exame inicial do recurso interposto pela parte sucumbente e a conseqüente manifestação escrita (contraa consequente manifestacoa escrita (contra-razões ou parecer), que deve compreender do recurso e do mérito do pedido que ele contém.

Com a instauração do processo, emerge, como objeto da atividade jurisdicional, o exame de duas relações jurídicas; uma, que é a lide propriamente dita, entre o impugnante e o Estado, este na condição de pretendente do crédito tributário, que é o ob- jeto último de processo; a outra é a relação processual que se estabelece, desde o momento inicial, entre o sujeito passivo da obrigação tributária e o Estado, este na condição de prestador da jurisdição.

A representação da Fazenda pode atuar tanto no plano da relação de direito material, quanto no da relação jurídica processual, quando esta apresentar algum vício, irregularidade ou omissão que a torne defeituosa ou ilegítima.

Compete-lhe, portanto, antes de discutir o mérito da causa, alegar como preliminares todas as arguições admissíveis, especialmente as peremptórias.

O juízo de admissibilidade tem por finalidade a aferição do preenchimento dos requisitos formais necessários para que o processo se constitua e tenha seguimento, atingindo, a final, o seu objetivo, que é a solução da lide.

Entre os requisitos que, a nosso sentir, devem ser examinados pelo representante da Fazenda encontram-se:

\section{1 - A competência do órgão julgador}

Deve-se levar em conta que a discussão de matéria tributária na esfera administrativa decorre de opção do sujeito passivo de exigência tributária, pois este pode levar a demanda diretamente ao Poder Judiciário. Porém, eleita a opção administrativa, o processo deverá ser constituído e conduzido na forma da legislação específica.

Os órgãos Julgadores de Segunda Instância Administrativa Tributária, obviamente, têm competência para reexaminar, em grau de recurso, decisões da primeira instância administrativa tributária, exceto casos de avocação (art.104, do Regimento Interno da JRF/DF), além de suas próprias decisões, em casos especiais previstos na legislação.

Cada Unidade Federada, ao fixar a competência em razão da matéria e do território, usa de linguagem própria, condicionando sempre, no contencioso, ao exame prévio por outro órgão administrativo tributário por ela definido. 
No Regimento Interno do Tribunal Administrativo de Recursos Fiscais do Rio Grande do Sul, sobre o assunto, encontramos os seguintes dispositivos: " ... é órgão de segunda instância administrativa no julgamento dos litígios suscitados entre a Fazenda Pública Estadual e seus contribuintes, decorrentes da aplicação da legislação tributária" (art.1ํ) e "... tem sua sede em Porto Alegre e jurisdição em todo território do Rio Grande do Sul" (art.3o).

Sergipe tratou a matéria de forma equivalente. O Regimento Interno do seu Conselho de Contribuintes dispõe: "... tem por finalidade o julgamento, em segunda e última instância administrativa, e em grau de recurso, dos processos administrativos fis cais." (art. $1^{\circ}$ ) e "... tem sede na Capital do Estado de Sergipe e jurisdição em todo o Território Estadual." (art.2을.

Como se pode ver, a competência terri torial na esfera administrativa estadual exclusiva, salvo os casos de avocação pelo Secretário da Fazenda (RS e PB).

\section{2 - A imparcialidade do Juízo}

É pressuposto processual de validade da decisão que o julgador (juiz, conselheiro ou vogal) que a profira ou dela participe sej imparcial, que não tenha motivação par atuar no interesse de uma das partes, pois interesse que deve prevalecer é o da justiça.

Objetivamente tem-se como imparcial aquele julgador que não se enquadra em nenhum dos motivos de impedimento ou de suspeição definidos na legislação pró pria, tais como:

a) interesse pessoal no feito (DF, RS, SC $\mathrm{RO}$, MS, e AL);

b) interesse de parentes, consangüíneos ou não, até o segundo grau inclusive (DF e $\mathrm{AL})$, terceiro grau inclusive (RS, RO, SE, SC e GO);

c) interesse de sociedade que se faça, ou tenha feito, parte como sócio, advogado, membro de diretoria ou conselho (DF, RS, $\mathrm{SC}, \mathrm{AL}$ e GO), sob vínculo permanente (RO);

d) houver proferido decisão de mérito ou emitido parecer no processo (DF, RS $\mathrm{GO}$ );

e) ter sido autor do procedimento fiscal GO)

Alguns regimentos estalecem normas procedimentais da "Exceção de Suspeição" (DF, MS e PE) no caso de não haver sido espontaneamente declarado o impedimento pelo julgador.

Evidentemente que ao eleger critérios objetivos de impedimento, o legislador não teve por escopo induzir a idéia de que quem julga em tais condições necessariamente parcial. O principal motivo do impedimento, além de evitar o constrangimento íntimo de o juiz ter que interferir em decisão que ele ou pessoas próximas tenham interesse, é o de preserver a imagem externa do julgador e do próprio juízo, pois não é suficiente que eles sejam imparciais, é importante que pareçam imparciais às partes.

\section{3 - Capacidade processual de parte}

Ter capacidade para ser parte é ter capacidade para ser sujeito de uma relação jurídica processual. Tal capacidade corresponde à capacidade jurídica de direito civil. Con tudo, a capacidade processual de ser parte mais ampla do que a capacidade civil. Assim, poderão eventualmente comparecer em juízo administrativo tributário, como autores, organismos ou coletividades não personalizadas, como a massa falida, os condomínios, a herança jacente, etc.

Distingue-se, assim, da capacidade de ser parte de uma determinada relação litigiosa (legitimatio ad causam), a capacidade para estar em juízo, ou legitimação processual (legitimatio ad processum), que é a capacidade para a prática de atos processuais. Os civilmente incapazes podem ser parte numa relação de origem tributária que lhes diga respeito e, nesse caso, têm legitimatio ad causam, porém, somente através de seus representantes (pais, tutores ou curadores) podem estar em juízo, o que significa que a legitimatio ad processum a esses corresponde e não a seus representados. Os maiores de
16 e menores de 21 anos têm capacidade parcial ou limitada para estar em juízo, devendo, portanto, ser assistidos por seus representantes legais.

A pessoa jurídica é representada (ou presentada, segundo Pontes de Miranda) por quem os respectivos atos constitutivos de signam, ou não designando, por seus diretores ou gerentes; a pessoa jurídica estrangeira, pelo gerente, representante ou administrador de sua filial, agência ou sucursal no Brasil; a massa falida, pelo seu síndico; o espólio, pelo inventariante; a he rança jacente ou vacante, pelo seu curador o condomínio, por seu administrador ou síndico, e as sociedades sem personalidade jurídica, por quem se encontrar em sua ad ministração.

Já quanto às provas da capacidade de representação, a legislação apresenta algum peculiaridade, por exemplo, no Rio Grand do Sul, estabelece que "a intervenção de dirigente (ou procurador) não produzirá nenhum efeito se, no ato, não for feita a prova de que os mesmos são detentores dos poderes de representação" (Lei no ${ }^{\circ}$ 6537/73, art.19, $\left.\S 2^{\circ}\right)$. Em outros Estados é admitid a prova posterior da condição de representante.

A irregularidade decorrente da não-observância das normas relativas à representação deve ser apurada pela Defesa da Fazenda, examinando todos os atos de nomeação dos representantes. Assim a pessoa jurídica, por exemplo, para provar que está regularmente representada, deve ter juntado aos autos todos os documentos societários aos autos todos os documentos societarios advogado (ou a outro agente autorizado em lei) foi assinada por procurador da pesso jurídica, deve ficar demonstrada, também, capacidade do outorgante (ou substabelecente) mediante a presença do respectivo instrumento. Deve ficar demonstrado qu quem assinou essa procuração era dirigente da pessoa jurídica, mediante a juntada dos atos constitutivos, ata de eleição do signatário, etc., onde se poderá verificar, com segurança, a regularidade dos atos praticados.

\section{4 - Capacidade postulatória}

Junto ao Poder Judiciário, a capacidade postulatória é privativa de advogado. Somente bacharel em direito, regularmente inscrito na Ordem dos Advogados do Brasil, pode postular em juízo em nome de outrem.

No processo administrativo tributário, a legislação específica dá tratamento diverso. Todas as Unidades da Federação, cuja legislação foi por nós examinada, atribuem capacidade postulatória ao sujeito passivo da obrigação tributária, podendo ele atuar no processo pessoalmente ou através de seus representates legais ("presentantes"). Já as normas relativas aos mandatários (procuradores) se apresentam com matizes diferentes nos diversos Membros da Federação. Alguns exigem que $O$ procurador seja advogado inscrito na $O A B(R S)$ ou "estagiário" da OAB (MG e PB) ou preposto de despachante estadual, gerente, ou contabilista (RJ). Outros não qualificam os procuradores (PE, $\mathrm{RO}, \mathrm{BA}$ e $\mathrm{PR}$ ).

Constatada a falta de capacidade postulatória ao signatário de peça impugnatória ou recursal, salvo norma expressa de convalescença do ato, este é nulo, portanto, insuscetível de retificação ou recuperação.

Entre as causas de nulidade do ato, arrolamos:

a) a inexistência de mandato, ou do seu instrumento (procuração) nos autos, sem a "caução de rato" quando admitida;

b) a falta, ao procurador, da qualificação exigida na lei (não é advogado regularmente inscrito na $O A B$, está impedido por lei ou por ato da $\mathrm{OAB}$, etc);

c) o não-cumprimento, pela parte, das determinações visando ao saneamento das irregularidades, no prazo fixado.

\section{5 - Legitimidade da parte}

Quem tiver legítimo interesse em relação material de natureza tributária em litígio com a Fazenda Pública tem legitimidade para ser parte na respectiva relação processual. 
O Regulamento do Processo Administrativo Fiscal da Bahia (art.10, parágrafo único) trata a matéria nos seguintes termos: "Tem legitimidade para postular todo aquele a quem a lei atribuir responsabilidade pelo pagamento de crédito tributário ou cumprimento de obrigação acessória ou que esteja submetido à exigência fiscal de qualquer espécie".

Disposição semelhante encontramos no Regulamento do Processo Administrativo-Tributário do Rio de Janeiro, em seu artigo 40: "São interessados para postular, além do contribuinte, todo aquele a quem a lei atribuir responsabilidade pelo pagamento do crédito tributário ou cumprimento da obrigação acessória".

As demais Unidades da Federação não destoam dessa linha de normatização, embora algumas delas não tenham atingido a clareza dos dispositivos transcritos.

\section{6 - Interesse de agir}

Em se tratando de recurso, não se pode perder de vista que só tem interesse par agir aquele que resultou vencido na decisão anterior e no limite de sua sucumbência.

\section{7 - Possibilidade jurídica do pedido}

O pedido formulado em Juízo deve estar fundamentado no ordenamento jurídico vi gente. O direito cuja aplicação é pedida, deve constar, pelo menos em tese, na esfera de competência do órgão julgador. A causa de pedir deve ser lícita e ter forma de composição prevista na legislação, além de inexistir limitação ao exercício do direito.

Minas Gerais, por exemplo, no artigo 106 do Regimento Interno de seu Conselho de Contribuintes, estabelece vedação aos seus órgãos julgadores de processo administrativo tributário, de julgarem declaração de inconstitucionalidade; negarem a aplicação de lei, decreto ou ato normativo e aplicarem a eqüidade. No Rio Grande do Sul, a incompetência de seu Tribunal Administrativo de Recursos Fiscais, para apreciar inconstituicionalidade de norma, é objeto de sua Súmula $n^{\circ} 3$.

\section{8 - Inépcia da inicial}

Entre as principais causas da inépcia da impuganação ou da peça recursal temos: a ausência de pedido ou causa de pedir e a formulação de pedido cujo atendimento é fática ou juridicamente impossivel, por exemplo, que seja dispensado o pagamento do crédito tributário, "relevada" a exigência de multa, etc., quando a legislação da respectiva Unidade da Federação não contempla ou veda expressamente tais providências.

Argüida e constatada a inépcia da inicial, a "petição será indeferida de plano" (RJ)

\section{9 - Preclusão}

As partes estão sujeitas à prática de certos atos e formalidades processuais, dentro de determinado lapso temporal, sob pena de perderem a oportunidade de realizá-los. Chama-se preclusão temporal a impossibilidade da parte praticar determinado ato processual, por haver perdido o momento ade quado para fazê-lo.

A preclusão pode ter como causa duas outras ordens de fatores, decorrendo daí mais duas espécies de preclusão, a lógica e a consumativa.

Há preclusão lógica quando a parte praticar determinado ato ou postular certa providência incompatível com sua própria conduta no mesmo ou em outro momento. Por exemplo, o impugnante condenado em primeira instância paga o crédito tributário e posteriormente, ainda no prazo legal para recorrer, intenta recurso à instância superior.

Ocorre preclusão consumativa, quando uma determinada faculdade processual fo proveitosamente exercida no momento adequado, tornando-se impossível a prática posterior (ainda que em caráter complementar) do mesmo ato. A parte a quem compet a interposição de "Recurso Voluntário" de decisão que lhe foi desfavorável em primeira instância administrativa, em 15 dias (RS), ao invés de se valer de todo o prazo, oferece seu recurso no oitavo dia, por exemplo, não lhe é permitido propor nova peti- ção recursal ou complementá-la, ainda que dentro do prazo previsto para o recurso.

\section{0 - Litispendência}

Diz-se que há litispendência quando já existe outro processo em que as mesmas partes discutem o mesmo assunto, por exemplo, o mesmo crédito tributário.

Afigura-se a litispendência no processo administrativo tributário quando, havendo uma ação pendente de decisão, outra idêntica a ela é proposta pelo mesmo autor, de modo que venham a se formar duas discussões a respeito da mesma relação jurídica, contra a mesma pessoa (Estado, no caso) e pela mesma causa.

Em tais circunstâncias, o remédio processual aplicável, para evitar o seguimento de duas causas de igual teor, é a "exceção de litispendência" cujo objetivo é a exclusão da segunda.

\section{1 - Definitividade da decisão} administrativa

O Código de Processo Civil (art.467) define coisa julgada material como "a eficácia, que torna imutável e indiscutível a sentença, não mais sujeita a recurso ordinário ou extraordinário".

A legislação que regula o procedimento tributário administrativo trata o assunto com normas conceituais que podem ser resumidas no seguinte: "São definitivas, na esfera administrativa, as decisões de que não caiba mais recurso". Também é norma generalizada na esfera administrativa, que a decisão, na parte que caiba recurso de ofício, não se torna definitiva enquanto este não for julgado.

Para que ocorra a imutabilidade que protege a decisão, tornando-a indiscutível em processos administrativos futuros, é necessário que tenha ocorrido a sua definitividade na própria relação jurídica de onde ela provém. Não há coisa julgada material sem prévia formação da coisa julgada formal.

\section{2 - Manifestação sobre o mérito}

Também desejamos abordar a manifestação do defensor dos interesses da Fazenda sobre o mérito da matéria sub judice, cuja importância não pode ser ignorada.

$\mathrm{Na}$ legislação do Rio Grande do Sul, há duas oportunidades para tanto. Primeiro, no "Parecer" prévio à própria distribuição dos autos ao juiz-relator, e mais tarde, quando do julgamento, na sustentação oral que faz após a apresentação do relatório.

A manifestação sobre o mérito tem singular relevo porque nela deve o defensor da Fazenda despir-se de sua condição de parte para assumir o papel de defensor da lei, igualando-se quase ao Ministério Público no desempenho de seu papel constitucional. Além do mais, seu "Parecer" tem servido para fundamentar, muito seguidamente, até mesmo o voto dos juízes, prestando-lhes assim preciosa colaboração.

II - Interposição dos recursos cabíveis, das decisões contrárias aos interesses da Fazenda (inclusive, procedimentos incidentais como "pedido de esclarecimento") e acompanhamento e sustentação dos recursos ex officio.

\section{1 - Recursos necessários (ex officio).}

Das decisões de primeira instância, em que a Fazenda Pública tenha sido vencida, no todo ou em parte, é obrigatório o reexame da matéria em instância superior, mediante recurso ex officio, com efeito suspensivo, interposto pelo prolator da decisão, no próprio instrumento. Tal expediente, que é compulsório em todas as Unidades da Federação, salvo circunstâncias especiais expressamente previstas da lei que rege o processo administrativo tributário.

As causas de dispensa do reexame, encontradas na legislação examinada são:

a) sucumbência da Fazenda em quantia reduzida, inferior ao valor de alçada fixando na lei (RS, GO, RJ, DF, ES, SC e MS). No Estado do Rio Grande do Sul, por exemplo, o valor de alçada é de $100 \mathrm{UPF} / \mathrm{RS}$, o que corresponde a CR $\$ 24.431,00$ cruzeiros reais (na moeda de agosto de 1993);

b) improcedência de crédito tributário, em qualquer valor, desde que se refira exclusivamente à obrigação acessória (RS, RJ 
e MS), compreendendo, portanto, apenas o cancelamento ou redução de multa por infração de natureza formal;

c) decisão absolutória (parcial ou total) que tenha sido embasada na existência de "erro de fato" no lançamento tributário (RS, RJ e MS), tal como, lançamento de valores já comprovadamente pagos ou decorrentes de erros de cálculo ou transporte de valores no auto de lançamento;

d) a declaração de extinção do processo com base em prova de pagamento do crédito tributário (CE).

Existem Unidades da Federação que estabelecem condições para o seguimento do recurso de ofício na segunda instância. A legislação do Estado de Goiás, por exemplo, faculta ao "Saneador de contenciosos administrativos tributários", o arquivamento do processo sem julgamento de mérito quando a "Representação da Fazenda" manifestar-se pela confirmação da decisão recorrida.

$\mathrm{Na}$ hipótese de não haver sido interposto o recurso obrigatório na própria decisão de primeira instância, cumpre ao funcionário que tiver que executar a decisão promover a representação àquela autoridade (RS), ou quando o processo ingressar na segunda instância, em grau de recurso voluntário, cabe a esta o conhecimento pleno do feito, se verificado que embora sujeito, também, ao recurso obrigatório este não tenha sido interposto (RS).

No Estado do Rio de Janeiro, o recurso ex officio de decisão de primeira instância é dirigido ao Superintendente de Tributação Estadual.

Mesmo quando não condicionada a seu pedido expresso de reforma da decisão recorrida, a tramitação do recurso ex officio deve ser acompanhada, em segunda instância, pelo defesa da Fazenda.

\section{2 - Recursos disponíveis}

A legislação das Unidades da Federação põe à disposição da respectiva Fazenda variados instrumentos que podem ser usados por seus representantes, quando estes entenderem que os interesses do erário público ão foram devidamente contemplados em decisões proferidas em segunda instância.

Dentro do critério que norteou a elaboção deste trabalho, faremos a seguir uma exposicão das várias espécies de recursos cabiveis, in casu, com a finalidade de possibilitar a melhor apreciação da ação do defensor da Fazenda.

Das decisões não-unânimes das Câmaras, Junta ou Conselho, cabe Recurso de Reconsideração ao próprio órgão (PR), Pedido de Reconsideração (MS, BA, SC, SP e DF) e "Recurso ao Conselho Pleno" (RJ).

Em Goiás o apelo é dirigido ao Consetho Pleno e chama-se Embargos e em São Paulo, da Decisão de Câmara que negar provimento ao Pedido de Reconsideração, cabe Recurso Extraordinário às Câmaras Reunidas.

Noutros Estados, como no Rio Grande do Sul, a Fazenda dispõe de Recurso Extraordinário ao Pleno quando a Decisão for adotada mediante voto de desempate do Presidente da Câmara. Em Minas Gerais, chama-se "Recurso de Revisão" à Câmara Superior (fala em voto de "qualidade" do Presidente). $\mathrm{Da}$ decisão não-unânime de Turma que reformar decisão de primeiro grau, em Pernambuco, impõe-se a interposição de recurso ex officio ao Pleno.

Por vezes, a competência da defesa da Fazenda, para interpor apelo necessário ou voluntário, sofre concorrência de outros órgãos administrativos fazendários, como é o caso de Rondônia, em que o Recurso de Revisão pode, também, ser intentado por Delegados Regionais, Diretores de Repartições Fiscais ou por promoção da Secretaria do próprio Conselho. Em São Paulo, os chefes e diretores de Repartições Fiscais e os Delegados Tributários têm competência concorrente com o Representante Fiscal para provocar o reexame através de Pedido de Reconsideração e de Pedido de Revisão.

Quando a decisão de uma Câmara, Turma ou Conselho (unicameral) divergir da de outra Câmara, Turma, Pleno ou Câmara Superior, Cabe Recurso de Revisão (RO), Recurso de Reconsideração (PR), Recurso Especial (CE), Recurso Extraordinário (RS),
Recurso Voluntário (PE), Recurso de Revista (BA e MG), "Recurso ao Conselho Pleno" (RJ) ou Pedido de Revisão (SP). Algumas Unidades Federadas admitem o reexame por divergência entre decisões plenárias ( $P R$ e BA), outras não (RS). Os Estados do Rio de Janeiro, Rio Grande do Sul e Pernambuco não provêem revisão da decisão com base em divergência com outra do mesmo órgão, enquanto que outros a admitem (CE, MG, RO e PR).

$\mathrm{Da}$ decisão de Câmara que deu provimento a recurso ex officio cabe Recurso Extraordinário ao Conselho Pleno (CE) e de decisão contrária à disposição expressa de lei ou à prova dos autos há Recurso Extraordinário às Câmaras Reunidas (SP).

É admitido, am alguns casos, recurso à instância especial - o Secretário da Fazenda ou Finanças - das decisões do Pleno, não-unânimes e contrárias à Fazenda (PR), decisões contrárias à legislação ou à prova dos autos, de que não caiba outro recurso (RJ) ou Recurso Extraordinário de decisão da Câmara Superior quando proferida mediante voto de "qualidade do Presidente" (MG) No Distrito Federal, das decisões da Junta, contrárias à Fazenda cabe recurso ao Prefe to (Lei no $4.191 / 62$, art.277).

\section{3 - Procedimentos incidentais}

Além de outros procedimentos incidentais de iniciativa da defesa da Fazenda, algumas Unidades prevêem "Recurso contra decisão do Presidente" (DF), "Exceção de Suspeição" (DF), Revisão por vício processual que acarrete cerceamento da defes (DF) e Pedido de Esclarecimento de decisão omissa, obscura ou contraditória (RS e PR)

III - Fiscalização da aplicação da legislação e prática de atos de instrução processual e correição.

A legislação atribui ao "Defensor dos interesses da Fazenda" poderes especiais para agir no procedimento tributário onde, em alguns casos, funciona como o principal instrutor do processo na esfera recursal, extrapolando a condição de representante de parte e adotando, por vezes, a postura de verdadeiro "promotor da justiça fiscal", na defesa, inclusive, dos interesses da parte que, em tese, se opõem aos de sua repreentada (a Fazenda Pública)

$\mathrm{Na}$ tentativa de consolidar as principais normas relativas ao assunto, chegamos aos seguintes itens:

1 - Prestar as informações solicitadas pelo Presidente e demais membros (PR, RS, RO, DF, PE, SE, CE, RJ e SC);

2 - Promover todas as diligências necesárias à boa instrução dos processos, podendo, inclusive, baixá-los à primeira instância para os fins pertinentes, sendo o encaminhamento comunicado, obrigatoriamente, ao Presidente (DF, PE, RJ, RS, e RO);

3 - Prestar assessoria contábil e fiscal aos membros do Conselho (RO);

4 - Requisitar a qualquer repartição estadual documentos que julgar necessários à instrução dos processos de que tenha vista, os quais the serão fornecidos com a maior brevidade (PR, RS e RJ);

5 - Zelar pela execução das leis, decretos e regulamentos que tenham de ser aplicados pelo órgão, promovendo junto a este as medidas necessárias (SE, RO, SC, RS, e RJ);

6 - Representar ao Secretário da Fazenda, ao Corregedor ou ao Presidente do órgão sobre quaisquer irregularidades verificadas nos processos, em detrimento da Fazenda ou dos contribuintes (SE, SC, RJ, PE, PR e RO);

7 - Representar administrativamente contra agentes do Fisco que, por omissão ou ação, dolosa ou culposa, verificada no processo tributário, causarem prejuízo ao Erário Estadual (CE)

IV - Fornecimento à administração fazendária de elementos de autocrítica e sugestōes capazes de proporcionar a avaliação e adequação de seu sistema normativo e operacional de fiscalização e exação.

Dentre as atividades da representação da Fazenda, é talvez a mais valiosa e que por si só justificaria a existência dos órgãos administrativos de julgamento do contencioso 
tributário, pois proporciona à administração uma avaliação da atividade fiscal e exacional, temporariamente próxima da ocorrência geradora da demanda.

No julgamento das questões tributárias pelo Poder Judiciário, em razão do distanciamento físico dos órgãos fazendários e até temporal devido às diversas instâncias que comporta, seria, nas condições atuais, im possível o acompanhamento do feito e o aproveitamento dos efeitos da decisão na reciclagem da normatização tributária em gera e do procedimento tributário em particular.

É evidente que a eficiência do sistema será maior na medida que o julgamento for menos demorado e que as informações cheguem mais rapidamente a seu centro de decisão, ainda que informalmente.

São exemplos de normas encontradas na legislação, sobre o assunto:

1 - Manter contato com o Diretor do Departamento de Administação Tributária, a fim de atender ao interesse dos serviços estabelecer unidade de orientação (RO);

2 - Comunicar à primeira instânci quaisquer irregularidades verificadas na instução processual, em detrimento da Fazenda ou do Contribuinte (RS);

3 - Apresentar ao Secretário da Fazend relatório minucioso de suas atividades no exercício anterior, mencionando as dúvidas e dificuldades surgidas na execução da legis lação tributária, sugerindo as medidas legis lativas e as providências que julgar adequadas ao aperfeiçoamento dos serviços de ação fiscal (SC e RJ);

4 - Sugerir às autoridades competentes, através da Presidência do Conselho Admi nistrativo Tributário, a adoção de medidas administrativas judiciais que visem a resguardar a Fazenda Pública de danos que possam ser causados por qualquer sujeito passivo de obrigação tributária (RJ).

\section{Conclusão}

$\mathrm{Na}$ apreciação da atividade do defensor da fazenda não nos limitamos a tratar das ações por ele desenvolvidas no processo ad- ministrativo tributário, segundo as legislações das diversas Unidades da Federação

Expusemos como as referidas legislações disciplinaram a atuação dos envolvidos no procedimento, com a intenção de, ressaltando a acão de todos, chamar a atencão para o papel do Defensor do Erário e deste modo possibilitar a apresentação de sugestões a serem formuladas por este Encontro para melhoria das normas processuais ad ministrativas tributárias em todo o territó rio nacional.

Se tal objetivo puder ser alcançado, ficaremos amplamente recompensados pelo esforço desenvolvido para a elaboracão deste despretencioso trabalho.

Legislação das unidades da Federação consultada

ALAGOAS- Regimento Interno do Conselho Tributa rio Estadual

BAHIA

- Decreto $n^{\circ} \mathbf{2 8 . 5 9 6 / 8 1}$

CEARÁ

- Lei no $12.145 / 93$

DISTRITO FEDERAL

- Regimento Interno da Junta de Recursos Fiscais ESPÍRITO SANTO

- Decreto n² 2.425-N/87

GOIÁS

- Regimento Interno do Conselho AdministrstivoTributário

- Lei no 8.792/79

MINAS GERAIS

- Regimento Interno do Conselho de Contribuintes do Estado

- Decreto no 23.780/84

MATO GROSSO DO SUL

- Lei n 331/92

PARAÍBA

- Código Tributário da Paraíba

PERNAMBUCO

- Lei $\mathrm{n}^{\mathrm{O}} 1.654 / 91$

- Decreto $\mathrm{n}^{\mathrm{0}} 15.229 / 91$

PARANÁ

- Lei no $8.933 / 89$
- Regimento Interno do Conselho de Contribuintes do Estado

RONDÔNIA

- Regulamento do Conselho de Recursos Fiscais (Decreto $\mathrm{n}^{\mathrm{0}} 4.656 / 90$ ).

Regimento Interno do Conselho de Recursos Fiscais do Estado

RIO GRANDE DO SUL

- Lei $\mathrm{n}^{\mathrm{O}} 6.537 / 73$

- Regimento Interno do Tribunal Administrativo de Recursos Fiscais
SANTA CATARINA

Regimento Interno do Conselho Estadual de Contribuintes

- Lei no 3.938/66

SERGIPE

- Regimento Interno do Conselho de Contribuintes do Estado

Nota

Tendo $\mathrm{em}$ vista que não dispúnhamos da legislação completa de todas as Unidades da Federação, as siglas 